\title{
MTHFR A1298C gene polymorphism on stroke risk: an updated meta-analysis
}

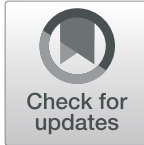

Xiaobo Dong ${ }^{1 \dagger}$, Jun Wang ${ }^{2 \dagger}$, Gesheng Wang ${ }^{1 *}$, Jiayue Wang ${ }^{1}$, Lei Wang ${ }^{1}$ and Yong Du ${ }^{1}$

\begin{abstract}
Background: Previous studies have shown the effect of MTHFR A1298C gene polymorphism on stroke risk. But the results of published studies remained inconclusive and controversial. So we conducted a meta-analysis to accurately estimate the potential association between MTHFR A1298C gene polymorphism and stroke susceptibility.

Methods: A systematic literature search on Embase, Pubmed, Web of Science, Cochrane Library, China National Knowledge Infrastructure (CNKI) and WanFang electronic database identified 40 articles including 5725 cases and 8655 controls. Strength of association was evaluated by pooled odds ratio (OR), 95\% confidence interval (Cl) and $p$ value. Funnel plots and Begger's regression test were applied for testing the publication bias. Statistical analysis of all data was performed by Stata 12.0 .
\end{abstract}

Results: The meta-analysis results indicated a significant relationship between MTHFR gene A1298C polymorphisms and stoke risk under the $\mathrm{C}$ allelic genetic model $(\mathrm{OR}=1.19,95 \% \mathrm{Cl}=1.07-1.32, p=0.001)$, dominant genetic model $(\mathrm{OR}=1.19,95 \% \mathrm{Cl}=1.06-1.33, p=0.004)$ and recessive genetic model $(\mathrm{OR}=1.43,95 \% \mathrm{Cl}=1.15-1.77, p=0.001)$. In subgroup analysis, we discovered obvious correlation in three genetic model of Asian, stroke type, adult by ethnicity, population, stroke type, source of control and case size. Additionally, in studies of control from hospital and case size equal 100, obvious correlation was also found in the three genetic model.

Conclusions: Our meta-analysis results indicated that there was evidence to support the correlation between MTHFR A1298C polymorphism and stroke susceptibility, especially in adults and ischemic stroke.

Keywords: MTHFR A1298C, Polymorphism, Stroke, Meta-analysis

\section{Introduction}

Stroke was a type of clinical syndrome caused by sudden neurological deficits after cerebral blood vessel rupture or occlusion. It had a very high rate of disability and was classified into ischemic stroke (IS) and hemorrhagic stroke (HS) [1, 2]. Genetic genes, high blood sugar, unhealthy lifestyles, high blood pressure, and hyperlipidemia were all high-risk factors for stroke, which similarly to high-risk factors for cardiovascular disease [3, 4].

\footnotetext{
* Correspondence: wanggesheng0623@163.com

${ }^{+}$Xiaobo Dong and Jun Wang contributed equally to this work.

'The Third department of Encephalopathy, Dongfang Hospital Beijing

University of Chinese Medicine, No. 6, Area 1, Fangxing Garden Fangzhuang, Fengtai District, Beijing 100078, China

Full list of author information is available at the end of the article
}

Methylenetrahydrofolate reductase (MTHFR) was a key enzyme that folic acid metabolizes in vivo. The activity of this enzyme can directly affect the plasma homocysteine content in the human body [5, 6]. C677T and A1298C were two common mutants in MTHFR. Their missense mutations resulted in the replacement of 677 base $C$ with $T$ and the substitution of A with $C$ in 1298 , which changed the amino acid structure of MTHFR and caused the decrease of MTHFR enzyme activity [7-10]. The homocysteine cannot be converted into the word methionine normally, which causes a significant increase in the homocysteine content in the blood, which increases the stroke susceptibility [11].

A meta-analysis study performed in 2013 firstly reported the association among MTHFR A1298C and

\section{$\triangle B M C$}

(C) The Author(s). 2021 Open Access This article is licensed under a Creative Commons Attribution 4.0 International License, which permits use, sharing, adaptation, distribution and reproduction in any medium or format, as long as you give appropriate credit to the original author(s) and the source, provide a link to the Creative Commons licence, and indicate if changes were made. The images or other third party material in this article are included in the article's Creative Commons licence, unless indicated otherwise in a credit line to the material. If material is not included in the article's Creative Commons licence and your intended use is not permitted by statutory regulation or exceeds the permitted use, you will need to obtain permission directly from the copyright holder. To view a copy of this licence, visit http://creativecommons.org/licenses/by/4.0/ The Creative Commons Public Domain Dedication waiver (http://creativecommons.org/publicdomain/zero/1.0/) applies to the data made available in this article, unless otherwise stated in a credit line to the data. 
stroke risk [12]. A meta-analysis study performed in 2014 reported the correlation between MTHFR A1298C polymorphism and adult stroke [13]. Although Kumar et al. [14] conducted a meta- analysis and indicated that genotyping of MTHFR gene A1298C polymorphism may be used as a predictor for the occurrence of ischemic stroke. However, just 20 articles were included in this study, and some articles published in Chinese journal were not included in the analysis. Incomplete article search may lead to unstable results. Later a metaanalysis study performed in 2018 reported the association among MTHFR A1298C polymorphism and IS risk [15]. In recent years, many studies [16-20] have reported the association among MTHFR A1298C polymorphism and stroke risk. But the results were still inconsistent. Therefore, the purpose of this metaanalysis was to investigate the relationship among MTHFR A1298C polymorphism and stroke risk by updating previous meta-analyses.

\section{Materials and methods Publication search}

Search in electronic databases such as PubMed, Cochrane Library, Web of Science, Embase, CNKI and WanFang using following terms: ("methylenetetrahydrofolate reductase" OR "A1298C" OR "MTHFR") AND ("apoplexy" OR "stroke" OR "brain infarction" OR "cerebrovascular disorder") AND ("polymorphism" OR "variant" OR "mutation") until August 2019. To ensure the relevant studies are included, two investigators independently searched the relevant literature and manually checked some major articles and reviews.

\section{Selection Criteria}

ALL selected studies complied with the inclusion criteria: (1) Full text can be searched in electronic databases; (2) Case-control studies on MTHFR A1298C and stroke susceptibility; (3) MTHFR A1298C genotype frequency can be provided. The main exclusion criteria include the following: (1) Repeat articles in other electronic databases (2) The design was not a casecontrol study; (3) Unpublished studies, meta- analysis and systematic reviews; (4) The genotype frequency of MTHFR A1298C was not provided. Referring to the systematic review and meta-analysis [PRISMA], we screened all retrieved documents and constructed an information flow chart using the final qualified data.

\section{Data extraction}

Two researchers screened the retrieved studies by inclusion and exclusion standard. We selected following information from the included researches: first author, publication years, study country / region, type of stroke, study population, control group source, sample size (case and control) and genotype type. we evaluated each included study by Newcastle-Ottawa Scale (NOS) [21]. And we used Hardy-Weinberg-equilibrium (HWE) to assess the gene distribution in control group [22]. In order to ensure the accuracy of the information extracted from the research, the third researcher will review the accuracy of the information extracted by the first two researchers, and the three researchers will resolve the disputed results through negotiation.

\section{Statistical analysis}

Odds ratio (OR) and 95\% confidence interval (CI) were calculated to estimate the relationship among MTHFR A1298C polymorphism and stroke susceptibility by different genetic comparison models: the $\mathrm{C}$ allele model $(\mathrm{C}$ and $\mathrm{A})$, recessive model $(\mathrm{CC}$ and $\mathrm{AA}+\mathrm{CA})$ and dominant model $(\mathrm{CC}+\mathrm{CA}$ and $\mathrm{AA})$. Heterogeneities of different genetic comparison models was evaluated by the $X^{2}$ based Q-statistic and $I^{2}$ [23, 24]. Significant Q statistic $(p<0.10)$ or $I^{2}>50 \%$ indicates that there was heterogeneity between studies. The pooled OR was estimated by fixed effect model (Mantel-Haenszel) when no heterogeneity existed. Otherwise, the pooled OR was estimated by random effect model. To determine the possible causes of heterogeneity, ethnicity (African, Caucasian and Asian), study population (children and adults), type of stroke (ischemic and hemorrhagic), control source (based on population and Hospitals) and case group sample sizes (less than 100 and greater than or equal to 100) were analyzed in subgroups. In addition, sensitivity analysis was performed on different genetic comparison models to evaluate the effect of a single research on pooled OR. We used Egger test and funnel plots to evaluate the potential publication bias [25]. Stata 12.0 was used to perform statistical analysis of all genetic comparison models.

\section{Results \\ Literature Search and Study Characteristics}

Flowcharts of the detailed selection process were shown in Fig. 1. A total of 5475 publications were searched in several electronic databases. After carefully reading the research title, content and abstract, the two researchers excluded 1496 duplicate documents, 3851 irrelevant papers, and read the remaining 128 articles in full text. Finally, our meta-analysis included 40 case-control publications that met the inclusion criteria (involving 5725 cases and 8655 controls). Four of the control groups did not meet HWE balance $(p<0.05)$. In the 40 case-control studies, 22 were conducted among Asian populations, 16 were Caucasian, and 2 were African population. Thirty-one studies were based on adults. Other 9 studies were based on children. Ten studies were based on IS. Four studies based on HS and other 


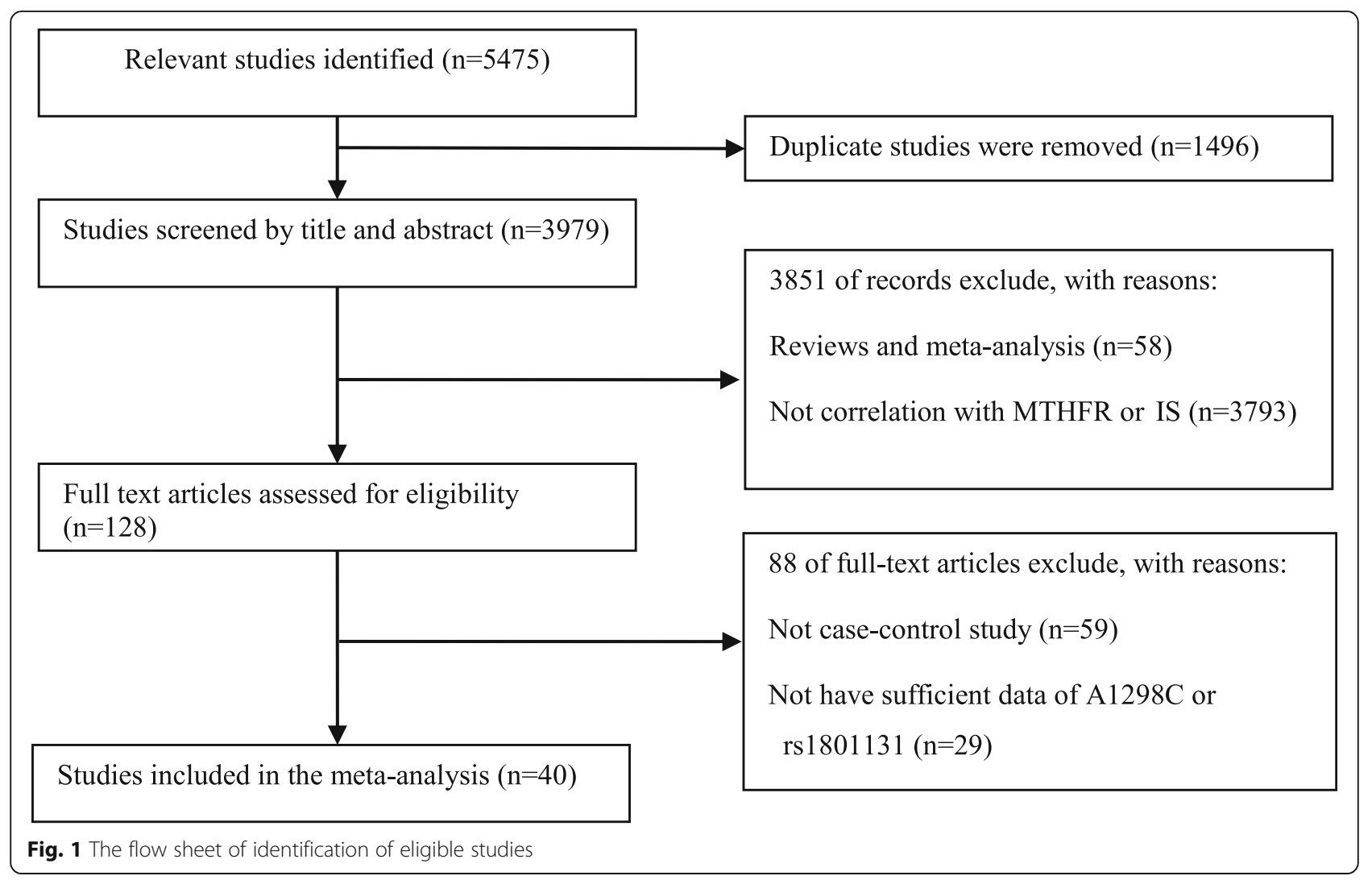

studies based on both (MIXED). Four studies based on population (PB), 21 studies based on hospital (HB). other studies based on no report (NR) in this article. The sample group of 21 studies was less than 100, and the sample group of the other 19 studies was greater than or equal to 100. The main features of the study and the genotype distribution results of the HWE test were shown in Table 1.

\section{Meta-analysis results}

The meta-analysis included 14,380 participants (5725 cases and 8655 controls) in 40 case-control studies (Table 2). The meta-analysis results indicated the polymorphisms in MTHFR A1298C gene had significant association with stoke risk under the $\mathrm{C}$ allelic genetic model $(\mathrm{OR}=1.19,95 \% \mathrm{CI}=1.07-1.32, p=0.001)$, dominant genetic model $(\mathrm{OR}=1.19,95 \% \mathrm{CI}=1.06-1.33, p=$ $0.004)$ and recessive genetic model $(\mathrm{OR}=1.43,95 \% \mathrm{CI}=$ $1.15-1.77, p=0.001$ ).

In ethnic subgroup analysis, MTHFR A1298C polymorphism was obviously correlated with increased risk of stroke under three genetic models of Asian population $(\mathrm{C}$ vs $\mathrm{A}: \mathrm{OR}=1.29,95 \% \mathrm{CI}=1.16-1.44, p<0.001$; $\mathrm{CC}+\mathrm{CA} \quad$ vs $\mathrm{AA}: \quad \mathrm{OR}=1.28, \quad 95 \% \mathrm{CI}=1.17-1.47, \quad p<$ $0.001 ; \mathrm{CC}$ vs $\mathrm{CA}+\mathrm{AA}: \mathrm{OR}=1.84,95 \% \mathrm{CI}=1.49-2.27$, $p<0.001)$. No significant correlation among MTHFR A1298C Polymorphism and stroke risk was found in the three genetic models of Caucasian and African. Among the three genetic models grouped by study population, only adult MTHFR A1298C polymorphisms were found to be obviously correlated with stroke susceptibility $(C$ vs $\mathrm{A}: \mathrm{OR}=1.18,95 \% \mathrm{CI}=1.07-1.32, p=0.002 ; \mathrm{CC}+\mathrm{CA}$ vs $\mathrm{AA}: \mathrm{OR}=1.19,95 \% \mathrm{CI}=1.06-1.34, p=0.008 ; \mathrm{CC}$ vs $\mathrm{CA}+\mathrm{AA}: \quad \mathrm{OR}=1.48, \quad 95 \% \mathrm{CI}=1.16-1.89, \quad p=0.002)$. There was no obvious association among MTHFR A1298C polymorphism and children stroke risk. Stratified analysis by stroke type found that MTHFR A1298C polymorphism was obviously correlated with increased stroke risk in the three genetic models of ischemic stroke $(\mathrm{C}$ vs $\mathrm{A}: \mathrm{OR}=1.22,95 \% \mathrm{CI}=1.09-1.37, p=0.002$; $\mathrm{CC}+\mathrm{CA} \quad$ vs $\mathrm{AA}: \mathrm{OR}=1.24, \quad 95 \% \mathrm{CI}=1.09-1.42, \quad p=$ 0.002 ; $\mathrm{CC}$ vs $\mathrm{CA}+\mathrm{AA}: \mathrm{OR}=1.38,95 \% \mathrm{CI}=1.12-1.69$, $p=0.002$ ). In the control source stratification, three control genetic models from hospitals found an obvious correlation among the MTHFR A1298C polymorphism and increased stroke risk $(C$ vs $A: ~ O R=1.24,95 \% C I=1.08-$ 1.42, $p=0.002 ; \mathrm{CC}+\mathrm{CA}$ vs $\mathrm{AA}: \mathrm{OR}=1.23,95 \% \mathrm{CI}=$ $1.06-1.44, \quad p=0.008 ; \quad \mathrm{CC}$ vs $\mathrm{CA}+\mathrm{AA}: \quad \mathrm{OR}=1.54$, $95 \% \mathrm{CI}=1.28-1.86, p=0.007)$. Finally, we stratified the case group according to whether the sample size was greater than or equal to 100 . The study discovered that MTHFR A1298C polymorphism was obviously correlated with increased stroke risk under the three genetic models with a sample size of 100 or more $(C$ vs $A: O R=$ 


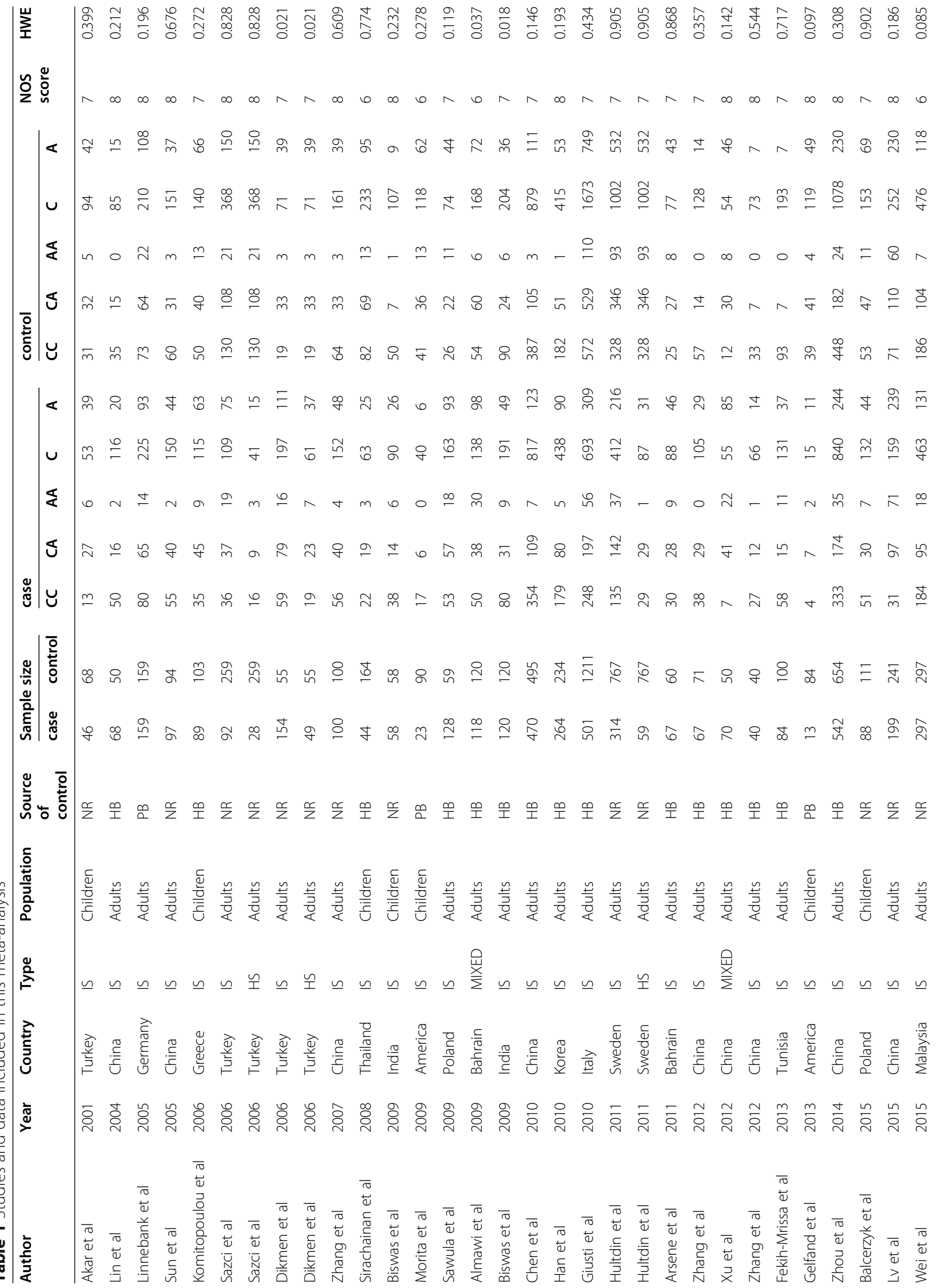




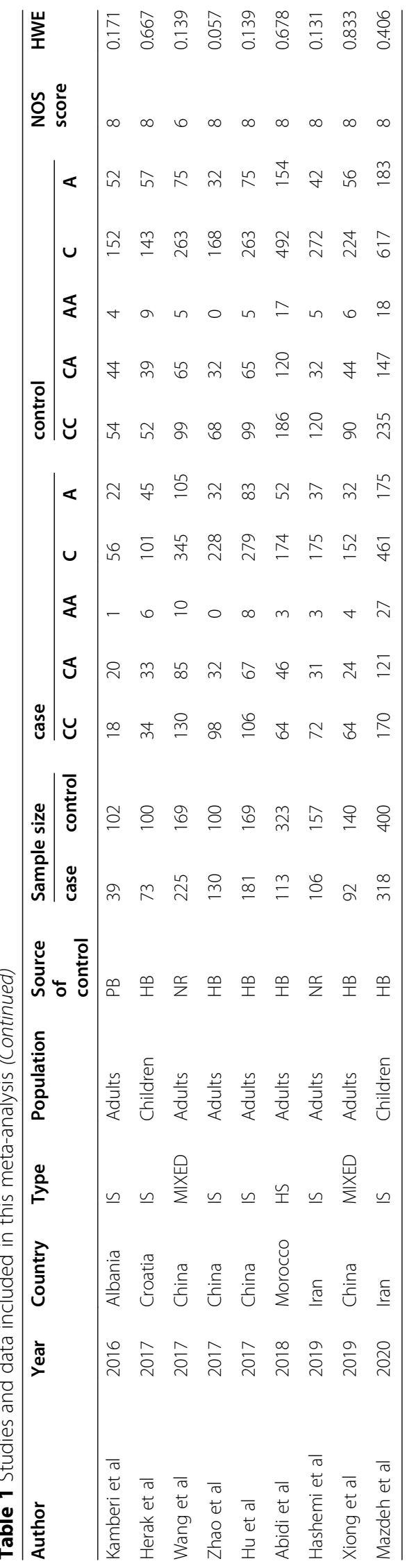


Table 2 Pooled ORs and 95\%Cls of the association between MTHFR A1298C polymorphism and stroke

\begin{tabular}{|c|c|c|c|c|c|c|c|c|c|c|c|c|c|}
\hline \multirow{2}{*}{$\begin{array}{l}\text { Total and } \\
\text { subgroups }\end{array}$} & \multirow[t]{2}{*}{ Studies } & \multicolumn{4}{|c|}{$C C+C A$ vs $A A$} & \multicolumn{4}{|c|}{$C C$ vs $C A+A A$} & \multicolumn{4}{|c|}{ C VS A } \\
\hline & & $\overline{\text { OR }}$ & $95 \% \mathrm{Cl}$ & $1^{2}$ & $\mathbf{P}$ & $\overline{O R}$ & $95 \% \mathrm{Cl}$ & $1^{2}$ & $P$ & $\overline{O R}$ & $95 \% \mathrm{Cl}$ & $1^{2}$ & $\mathbf{P}$ \\
\hline Total & 40 & 1.19 & $1.06 \sim 1.33$ & $51.8 \%$ & $<0.001$ & 1.43 & $1.15 \sim 1.77$ & $40.6 \%$ & 0.006 & 1.19 & $1.07 \sim 1.32$ & $61.1 \%$ & $<0.001$ \\
\hline \multicolumn{14}{|l|}{ Ethnicity } \\
\hline Asian & 22 & 1.28 & $1.17 \sim 1.47$ & $40.9 \%$ & 0.025 & 1.84 & $1.49 \sim 2.27$ & $0.0 \%$ & 0.057 & 1.29 & $1.16 \sim 1.44$ & $36.8 \%$ & 0.044 \\
\hline Caussian & 16 & 0.99 & $0.85-1.17$ & $29.2 \%$ & 0.131 & 1.10 & $0.81 \sim 1.50$ & $44.0 \%$ & 0.031 & 1.01 & $0.88 \sim 1.16$ & $48.0 \%$ & 0.017 \\
\hline African & 2 & 2.38 & $0.43-13.19$ & $91.6 \%$ & 0.001 & 3.31 & $0.04 \sim 276.07$ & $87.8 \%$ & 0.004 & 2.63 & $0.33 \sim 20.97$ & $95.2 \%$ & $<0.001$ \\
\hline \multicolumn{14}{|l|}{ Population } \\
\hline Child & 9 & 1.20 & $0.85 \sim 1.69$ & $58.9 \%$ & 0.013 & 1.25 & $0.79 \sim 2.00$ & $29.0 \%$ & 0.187 & 1.15 & $0.86 \sim 1.54$ & $66.1 \%$ & $0 . .003$ \\
\hline Adult & 31 & 1.19 & $1.06 \sim 1.34$ & $51.1 \%$ & 0.001 & 1.48 & $1.16 \sim 1.89$ & $45.0 \%$ & 0.005 & 1.18 & $1.07 \sim 1.32$ & $60.9 \%$ & $<0.001$ \\
\hline \multicolumn{14}{|l|}{ Stroke type } \\
\hline IS & 32 & 1.24 & $1.09 \sim 1.42$ & $56.6 \%$ & $<0.001$ & 1.38 & $1.12 \sim 1.69$ & $28.4 \%$ & 0.076 & 1.22 & $1.09 \sim 1.37$ & $63.0 \%$ & $<0.001$ \\
\hline $\mathrm{HS}$ & 4 & 0.89 & $0.67 \sim 1.18$ & $0.0 \%$ & 0.811 & 0.79 & $0.23 \sim 2.65$ & $64.5 \%$ & 0.037 & 0.88 & $0.70 \sim 1.10$ & $0.0 \%$ & 0.494 \\
\hline MIXED & 4 & 1.09 & $0.77 \sim 1.56$ & $36.8 \%$ & 0.191 & 2.39 & $1.09 \sim 5.22$ & $55.9 \%$ & 0.078 & 1.27 & $0.91 \sim 1.78$ & $60.2 \%$ & 0.057 \\
\hline \multicolumn{14}{|c|}{ Source of control } \\
\hline $\mathrm{HB}$ & 21 & 1.23 & $1.06 \sim 1.44$ & $51.4 \%$ & 0.011 & 1.54 & $1.28 \sim 1.86$ & $40.9 \%$ & 0.033 & 1.24 & $1.08 \sim 1.42$ & $60.7 \%$ & $<0.001$ \\
\hline PB & 4 & 0.88 & $0.47 \sim 1.62$ & $52.7 \%$ & 0.003 & 0.61 & $0.33 \sim 1.11$ & $39.5 \%$ & 0.175 & 0.86 & $0.49 \sim 1.50$ & $68.8 \%$ & 0.022 \\
\hline NR & 15 & 1.19 & $0.98 \sim 1.44$ & $57.9 \%$ & 0.068 & 1.38 & $1.12 \sim 1.70$ & $37.4 \%$ & 0.071 & 1.18 & $1.01 \sim 1.39$ & $59.2 \%$ & 0.002 \\
\hline \multicolumn{14}{|l|}{ Case size } \\
\hline$<100$ & 21 & 1.28 & $1.00 \sim 1.65$ & $61.3 \%$ & $<0.001$ & 1.36 & $0.92 \sim 2.01$ & $36.9 \%$ & 0.050 & 1.25 & $1.00 \sim 1.57$ & $69.8 \%$ & $<0.001$ \\
\hline$\geq 100$ & 19 & 1.14 & $1.02 \sim 1.28$ & $36.8 \%$ & 0.055 & 1.46 & $1.12 \sim 1.88$ & $47.5 \%$ & 0.013 & 1.16 & $1.05 \sim 1.28$ & $46.8 \%$ & 0.013 \\
\hline
\end{tabular}

1.16, $95 \% \mathrm{CI}=1.05-1.28, \quad p=0.003 ; \mathrm{CC}+\mathrm{CA}$ vs $\mathrm{AA}$ : $\mathrm{OR}=1.14,95 \% \mathrm{CI}=1.02-1.28, p=0.020 ; \mathrm{CC}$ vs $\mathrm{CA}+$ $\mathrm{AA}: \mathrm{OR}=1.46,95 \% \mathrm{CI}=1.12-1.88, p=0.004$ ) (Fig. 2).

In order to evaluate the stability of this meta-analysis, the sensitivity analysis of this study excluded each included study one by one to compare the difference between the pooled OR before and after exclusion. The results of this analysis were very stable (Fig. 3). We used Begg' $s$ funnel plot to estimate publication bias and found no publication in the three genetic models ( $\mathrm{C}$ vs $\mathrm{A}: p=0.742 ; \mathrm{CC}+\mathrm{CA}$ vs $\mathrm{AA}: p=0.825 ; \mathrm{CC}$ vs $\mathrm{CA}+\mathrm{AA}$ : $p=0.138)$ (Fig. 4).

\section{Discussion}

In recent years, there have been many studies on $M T H F$ $R$ A1298C polymorphism and stroke susceptibility [17, 19, 26-50]. In 2001, Akar et al. firstly found no association among MTHFR A1298C polymorphism and the ischemic stroke risk in Turkish children [51]. In 2004, the study by Lin et al. focused on adult ischemic stroke in China and found that the CC genotype and C allele frequency had no obvious difference between the cases and controls [52]. Biswas et al. [53] found that MTHFR 1298 A $>$ C showed significant alleles and genotypes associated with disease phenotypes in the Indian child population. With increasing research among MTHFR A1298C polymorphism and stroke susceptibility, Lv et al. [12] performed a meta-analysis of MTHFR gene A1298C and stroke. In this meta-analysis, 13 studies with 1974 cases and 2660 controls were extracted to assess the potential correlation. Overall analysis indicated that MTHFR A1298C was significantly associated with the stroke risk only in the heterozygote comparison and in the dominant model. Zhang constructed a meta-analysis of $M T H F$ $R$ A1298C polymorphism and stroke risk in adults [13]. 15 researches with 2361 cases and 2653 controls were included in final meta-analysis. Comprehensive analysis results showed that the polymorphism of MTHFR gene A1298C was significantly correlated with adult stroke in allelic model, dominant, additive and recessive models. Because the two meta-analyses came from different populations and sample sizes are different, these studies have shown inconsistent results. Since 2014, there have been another 25 studies on MTHFR gene A1298C polymorphism and stroke. Therefore, we upgraded a metaanalysis of MTHFR gene A1298C polymorphism and stroke susceptibility.

This meta-analysis resolved the correlation among MTHFR A1298C polymorphism and stroke susceptibility. The comprehensive data of the study showed that MTHFR A1298C polymorphism was a probable risk factor for stroke in dominant model $(\mathrm{CC}+\mathrm{CA}$ vs $\mathrm{AA})$, recessive model ( $\mathrm{CC}$ vs $\mathrm{CA}+\mathrm{AA})$ and allele model $(\mathrm{C}$ vs A). In stratified analysis based on race, study population, 

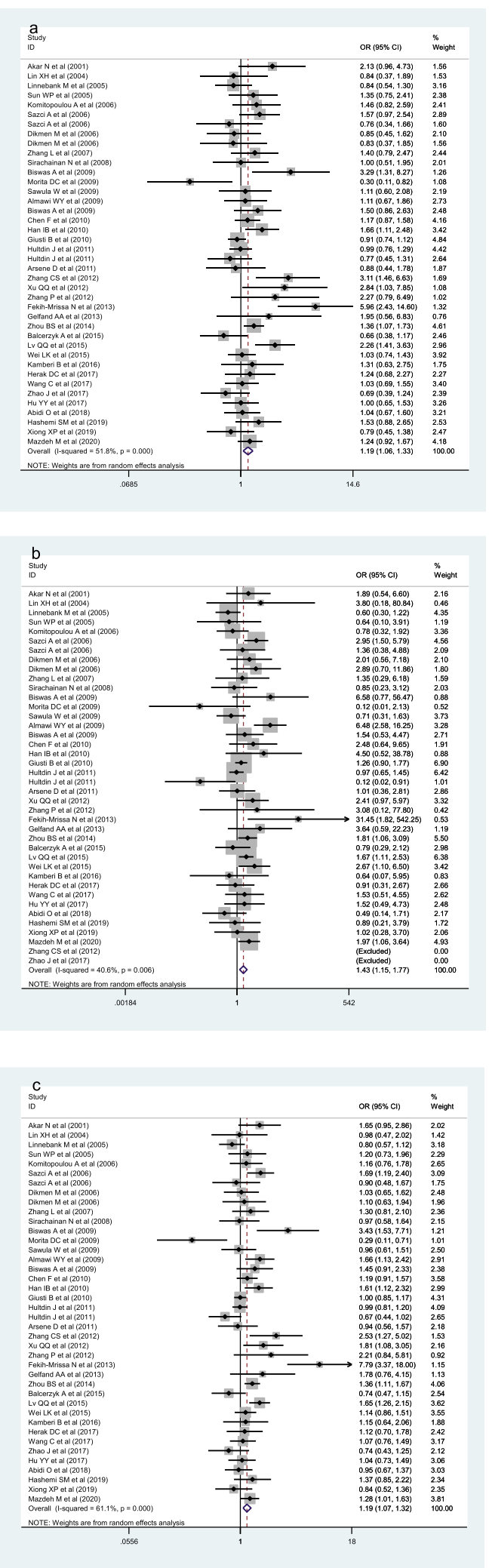

Fig. 2 Forest plots of the MTHFR A1298C polymorphism under different genetic models. $\mathbf{a}$ is the model of CC + CA VS TT; $\mathbf{b}$ is the model of CC VS CA + AA; $\mathbf{c}$ is the model of C VS A

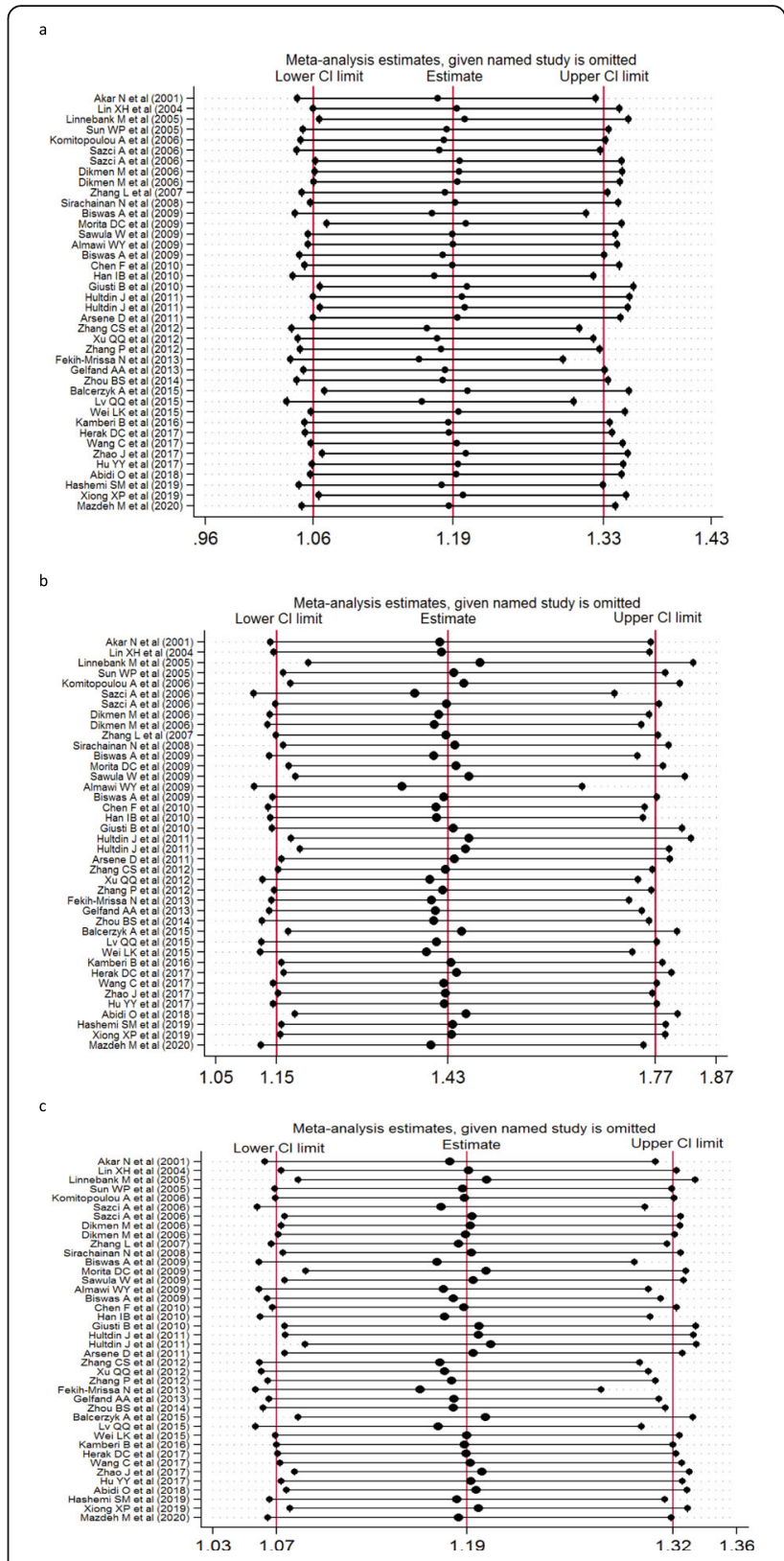

Fig. 3 Sensitivity analysis examining the association between the MTHFR A1298C polymorphism and risk of stroke under these model $(C C+C A$ VS AA, CC VS CA + AA, C VS A

stroke type, source of controls population and sample size of cases, a significant association was discovered among MTHFR A1298C polymorphism and stroke in three genetic models of Asians. In Caussian and African, MTHFR A1298C polymorphism was not significantly correlated with stroke. In stratified analysis according to study population, it was discovered that MTHFR A1298C polymorphism was obviously correlated with stroke in adults. But the correlation between MTHFR A1298C polymorphism and stroke in children lacked corresponding evidence. In stratified analysis of stroke 
a

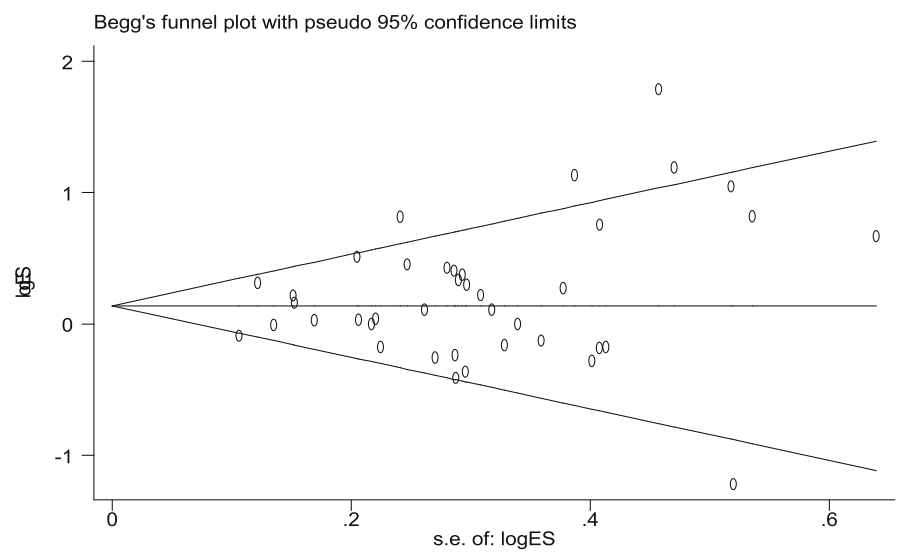

b

Begg's funnel plot with pseudo $95 \%$ confidence limits

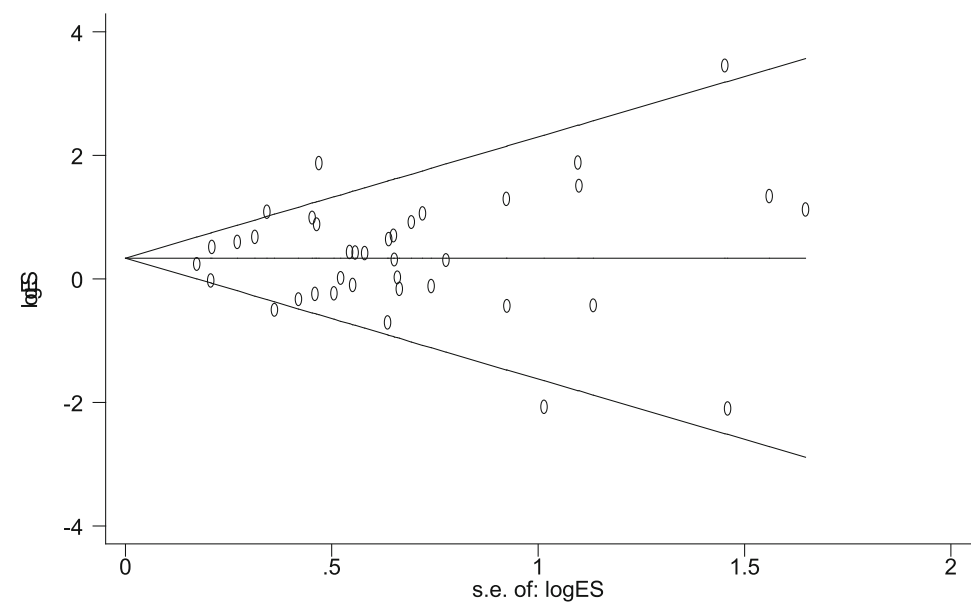

C

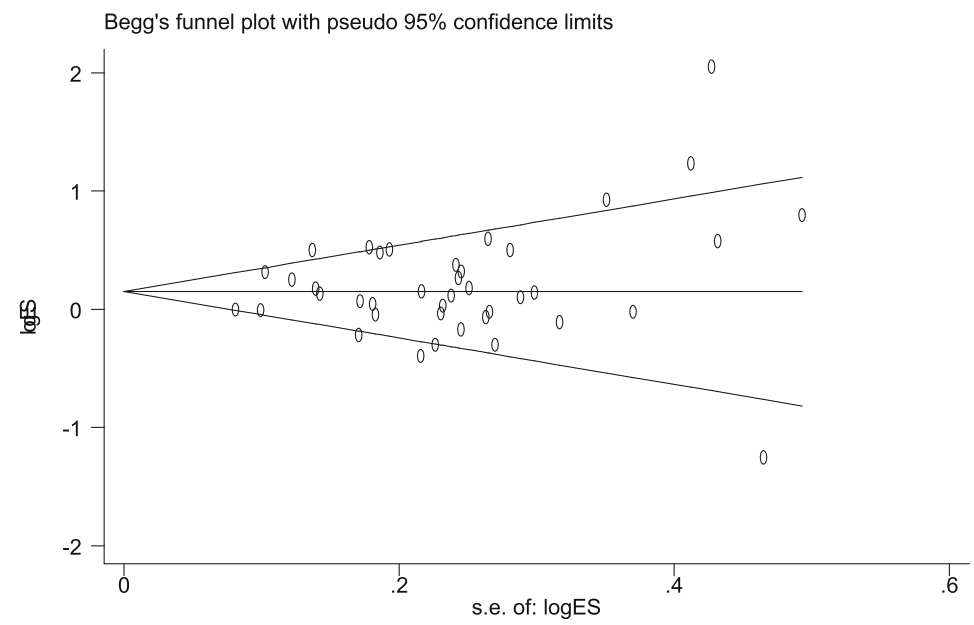

Fig. 4 Begg's funnel plot for publication bias analysis. $\mathbf{a}$ is the model of CC +CA VS T; $\mathbf{b}$ is the model of CC VS CA + AA; $C$ is the model of C VS A 
types, the association among MTHFR A1298C polymorphism and stroke was found only in ischemic stroke. The stratified analysis of source of the control group showed that there was obvious correlation among MTHFR A1298C polymorphism and stroke in hospital study. The stratified analysis of the sample size showed that the correlation among MTHFR A1298C polymorphism and stroke was found only when the number of samples in the case group was greater than or equal to 100 . The above analysis showed that the source of control group and the sample size of case group may be the influencing factors of the correlation study among MTHFR A1298C polymorphism and stroke. This was undiscovered in early meta-analysis. Although Kumar et al. [14] conducted a meta- analysis on association between A1298C polymorphism and risk of ischemic stroke. However, just 20 articles were included in this study, and some articles published in Chinese journal were not included in the analysis. The biological mechanism of the association between A1298C and stroke has not been confirmed. Study [54] indicated that MTHFR gene can encode MTHFR enzyme, which plays a key role in regulating cellular homocysteine (Hcy) and folate metabolism by catalyzing the conversion of 5,10methylpentylenetetrahydrofolate to 5- methyltetrahydrofolate, and elevated homocysteine level in blood circulation is considered as an independent risk factor for cerebral, coronary and peripheral atherosclerosis [55].

This meta-analysis has several limitations. Our results show the genetic differences in ethnic differences and stroke risk, but the study only includes Asian, Caucasian and African populations, and there are few studies in African populations, and there are no corresponding studies for other ethnic populations. The occurrence of stroke is often caused by the interaction of genetic factors and environmental factors. This study is only conducted from the perspective of genetics without the influence of environmental exposure. In previous studies, especially in meta-analysis, the data was still insufficient. We have checked as many articles as possible, but many studies have omitted data, such as control sources and genetic testing methods.

In conclusion, we found obvious correlation among MTHFR A1298C and stroke risk in Asians, adults and ischemic strokes. However, for the Caucasian, African, children and hemorrhagic stroke, the risk of MTHFR A1298C could not be confirmed because of the relatively limited sample size. In addition, sample size of case group and source of control group would also have an impact on the results in the stratified analysis of this study. Therefore, in future research, we can explore more about the correlation among MTHFR A1298C and stroke in other races (except for Asian population), children, and hemorrhagic stroke.
Acknowledgements

We appreciate all the families and individuals who collaborated on this research.

\section{Ethical Statement}

Not applicable.

\section{Authors' contributions}

Manuscript writing, editing and review were conducted by XD and GW; JW and JW participated in the articles search; LW and YD performed data analysis and evaluation the quality of the selected studies. The author(s) read and approved the final manuscript.

\section{Funding}

Not applicable.

Availability of data and materials

Not applicable.

\section{Declarations}

Ethics approval and consent to participate

Not applicable.

\section{Consent for publication}

Not applicable.

\section{Competing interests}

The authors declare that they have no competing interests.

\section{Author details}

${ }^{1}$ The Third department of Encephalopathy, Dongfang Hospital Beijing University of Chinese Medicine, No. 6, Area 1, Fangxing Garden Fangzhuang, Fengtai District, Beijing 100078, China. ${ }^{2}$ Department of Neurology, Chinese PLA General Hospital, Beijing 100039, China.

Received: 14 April 2021 Accepted: 30 May 2021

Published online: 25 September 2021

\section{References}

1. Francis J, Raghunathan S, Khanna P. The role of genetics in stroke. Postgrad Med J. 2007:83(983):590-5.

2. Malik R, Dichgans M. Challenges and opportunities in stroke genetics. Cardiovasc Res. 2018;114(9):1226-40.

3. Bogiatzi C, Hackam DG, McLeod Al, Spence JD. Secular trends in ischemic stroke subtypes and stroke risk factors. Stroke. 2014;45(11):3208-13.

4. Guzik A, Bushnell C. Stroke Epidemiology and Risk Factor Management. Continuum (Minneapolis, Minn). 2017;23(1, Cerebrovascular Disease):15-39.

5. Bagley PJ, Selhub J. A common mutation in the methylenetetrahydrofolate reductase gene is associated with an accumulation of formylated tetrahydrofolates in red blood cells. Proc Natl Acad Sci U S A. 1998;95(22): 13217-20.

6. Stankova J, Lawrance AK, Rozen R. Methylenetetrahydrofolate reductase (MTHFR): a novel target for cancer therapy. Curr Pharm Des. 2008;14(11): $1143-50$

7. Perales Dávila J. Martínez de Villarreal LE, Triana Saldaña H, Saldívar Rodríguez D, Barrera Saldaña H, Rojas Martínez a, et al. [folic acid levels, homocysteine and polymorphism of methylenetetrahydrofolate reductase enzyme (MTHFR) in patients with pre-eclampsia and eclampsia]. Ginecologia y Obstetricia de Mexico. 2001;69:6-11.

8. Pramukarso DT, Faradz SM, Sari S, Hadisaputro S. Association between methylenetetrahydrofolate reductase (MTHFR) polymorphism and carotid intima medial thickness progression in post ischaemic stroke patient. Ann Transl Med. 2015:3(21):324.

9. Song Y, Li B, Wang C, Wang P, Gao X, Liu G. Association between 5,10Methylenetetrahydrofolate Reductase C677T gene polymorphism and risk of ischemic stroke: a Meta-analysis. J Stroke Cerebrovasc Dis. 2016;25(3):679-87.

10. Toffoli G, De Mattia E. Pharmacogenetic relevance of MTHFR polymorphisms. Pharmacogenomics. 2008;9(9):1195-206. 
11. Zhao M, Wang X, He M, Qin X, Tang G, Huo Y, et al. Homocysteine and stroke risk: modifying effect of Methylenetetrahydrofolate Reductase C677T polymorphism and folic acid intervention. Stroke. 2017;48(5):1183-90.

12. Lv Q, Lu J, Wu W, Sun H, Zhang J. Association of the methylenetetrahydrofolate reductase gene $\mathrm{A} 1298 \mathrm{C}$ polymorphism with stroke risk based on a meta-analysis. Genet Molecular Res. 2013;12(4):6882-94.

13. Zhang MJ, Hu ZC, Yin YW, Li BH, Liu Y, Liao SQ, et al. A meta-analysis of the relationship between MTHFR gene A1298C polymorphism and the risk of adult stroke. Cerebrovascular Diseases (Basel, Switzerland). 2014;38(6):425-32.

14. Kumar A, Sharma R, Misra S, Nath M, Kumar P. Relationship between methylenetetrahydrofolate reductase (MTHFR) gene (A1298C) polymorphism with the risk of stroke: a systematic review and metaanalysis. Neurol Res. 2020;42(11):913-22.

15. Sarecka-Hujar B, Kopyta I, Skrzypek M. Is the 1298A>C polymorphism in the MTHFR gene a risk factor for arterial ischaemic stroke in children? The results of meta-analysis. Clin Exp Med. 2018;18(3):337-45.

16. Abidi O, Haissam M, Nahili H, El Azhari A, Hilmani S, Barakat A. Methylenetetrahydrofolate Reductase gene polymorphisms (C677T and A1298C) and hemorrhagic stroke in Moroccan patients. J Stroke Cerebrovasc Dis. 2018;27(7):1837-43.

17. Hashemi SM, Ramroodi N, Amiri Fard H, Talebian S, Haghighi Rohani M, Rezaei M, et al. Common Variations in Prothrombotic Genes and Susceptibility to Ischemic Stroke in Young Patients: A Case-Control Study in Southeast Iran. Medicina (Kaunas, Lithuania). 2019;55(2):47.

18. Kamberi B, Kamberi F, Spiroski M. Vascular genetic variants and ischemic stroke susceptibility in Albanians from the republic of Macedonia. Open Access Macedonian J Med Sci. 2016;4(4):556-64.

19. Lv QQ, Lu J, Sun H, Zhang JS. Association of methylenetetrahydrofolate reductase (MTHFR) gene polymorphism with ischemic stroke in the eastern Chinese Han population. Genet Mole Res. 2015;14(2):4161-8.

20. Mazdeh M, Khazaie M, Omrani MD, Noroozi R, Komaki A, Karimi M, et al. Association between methylene tetrahydrofolate reductase polymorphisms and risk of ischemic stroke. Int J Neurosci. 2020:1-5.

21. Stang A. Critical evaluation of the Newcastle-Ottawa scale for the assessment of the quality of nonrandomized studies in meta-analyses. Eur J Epidemiol. 2010;25(9):603-5.

22. Liu $H$, Hu Y. [Hardy-Weinberg equilibrium in genetic epidemiology]. Zhong nan da xue xue bao Yi xue ban. 2010;35(1):90-3.

23. Higgins JP, Thompson SG. Quantifying heterogeneity in a meta-analysis. Stat Med. 2002;21(11):1539-58.

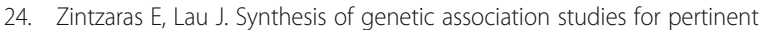
gene-disease associations requires appropriate methodological and statistical approaches. (0895-4356 (Print)).

25. Irwig L, Macaskill P, Berry G, Glasziou P. Bias in meta-analysis detected by a simple, graphical test. Graphical test is itself biased. BMJ (Clinical research ed). 1998;316(7129):470; author reply -1.

26. Almawi WY, Khan A, Al-Othman SS, Bakhiet M. Case-control study of methylenetetrahydrofolate reductase mutations and hyperhomocysteinemia and risk of stroke. J Stroke Cerebrovasc Dis. 2009;18(5):407-8.

27. Balcerzyk A, Niemiec P, Kopyta I, Emich-Widera E, Pilarska E, PienczkRęcławowicz K, et al. Methylenetetrahydrofolate reductase gene A1298C polymorphism in pediatric stroke--case-control and family-based study. J Stroke Cerebrovasc Dis. 2015;24(1):61-5.

28. Biswas A, Ranjan R, Meena A, Akhter MS, Yadav BK, Munisamy M, et al. Homocystine levels, polymorphisms and the risk of ischemic stroke in young Asian Indians. J Stroke Cerebrovasc Dis. 2009;18(2):103-10.

29. Coen Herak D, Lenicek Krleza J, Radic Antolic M, Horvat I, Djuranovic V, Zrinski Topic R, et al. Association of Polymorphisms in coagulation factor genes and enzymes of Homocysteine metabolism with arterial ischemic stroke in children. Clin Appl Thrombosis/Hemostasis. 2017;23(8):1042-51.

30. Dikmen M, Ozbabalik D, Gunes HV, Degirmenci I, Bal C, Ozdemir G, et al. Acute stroke in relation to homocysteine and methylenetetrahydrofolate reductase gene polymorphisms. Acta Neurol Scand. 2006;113(5):307-14.

31. Fekih-Mrissa N, Mrad M, Klai S, Mansour M, Nsiri B, Gritli N, et al. Methylenetetrahydrofolate reductase (C677T and A1298C) polymorphisms, hyperhomocysteinemia, and ischemic stroke in Tunisian patients. J Stroke Cerebrovasc Dis. 2013;22(4):465-9.

32. Giusti B, Saracini C, Bolli P, Magi A, Martinelli I, Peyvandi F, et al. Early-onset ischaemic stroke: analysis of 58 polymorphisms in 17 genes involved in methionine metabolism. Thromb Haemost. 2010;104(2):231-42.
33. Han IB, Kim OJ, Ahn JY, Oh D, Hong SP, Huh R, et al. Association of methylenetetrahydrofolate reductase (MTHFR 677C>T and 1298A>C) polymorphisms and haplotypes with silent brain infarction and homocysteine levels in a Korean population. Yonsei Med J. 2010;51(2): 253-60.

34. Hultdin J, Van Guelpen B, Winkvist A, Hallmans G, Weinehall L, Stegmayr B, et al. Prospective study of first stroke in relation to plasma homocysteine and MTHFR 677C>T and 1298A>C genotypes and haplotypes - evidence for an association with hemorrhagic stroke. Clin Chem Lab Med. 2011;49(9): 1555-62.

35. Komitopoulou A, Platokouki H, Kapsimali Z, Pergantou H, Adamtziki E, Aronis S. Mutations and polymorphisms in genes affecting hemostasis proteins and homocysteine metabolism in children with arterial ischemic stroke. Cerebrovasc Dis (Basel, Switzerland). 2006;22(1):13-20.

36. Linnebank M, Montenarh M, Kölsch H, Linnebank A, Schnez K, Schweichel $D$, et al. Common genetic variants of homocysteine metabolism in ischemic stroke: a case-control study. Eur J Neurol. 2005;12(8):614-8.

37. Morita DC, Donaldson A, Butterfield RJ, Benedict SL, Bale JF Jr. Methylenetetrahydrofolate reductase gene polymorphism and childhood stroke. Pediatr Neurol. 2009;41(4):247-9.

38. Sawuła W, Banecka-Majkutewicz Z, Kadziński L, Jakóbkiewicz-Banecka J, Wegrzyn G, Nyka W, et al. Homocysteine level and metabolism in ischemic stroke in the population of northern Poland. Clin Biochem. 2009;42(6):442-7.

39. Sazci A, Ergul E, Tuncer N, Akpinar G, Kara I. Methylenetetrahydrofolate reductase gene polymorphisms are associated with ischemic and hemorrhagic stroke: dual effect of MTHFR polymorphisms C677T and A1298C. Brain Res Bull. 2006;71(1-3):45-50.

40. Wei LK, Au A, Menon S, Gan SH, Griffiths LR. Clinical relevance of MTHFR, eNOS, ACE, and ApoE gene polymorphisms and serum vitamin profile among Malay patients with ischemic stroke. J Stroke Cerebrovasc Dis. 2015; 24(9):2017-25

41. Zhou BS, Bu GY, Li M, Chang BG, Zhou YP. Tagging SNPs in the MTHFR gene and risk of ischemic stroke in a Chinese population. Int J Mol Sci. 2014;15(5):8931-40.

42. Chen F, Feng Q, Zheng H. Study on correlation between the MTHFR A1298C morphisms and ischemic cerebravascular disease. Chin J Practical Nervous Diseases. 2010;13(18):1-4.

43. Hu Y, Hou L, Ji F, Pan H. The analysis of polymorphism relationship of MTHF R gene and ischeme stroke in Jiamusi. Heilongjiang Med Pharmacy. 2017; 40(01):89-91.

44. WANG C, Yu L, Ji F, Lei L. Analysis of the frequency of MTHFR gene polymorphism in stroke patients in eastern Heilongjiang. Heilongjiang Med Sci. 2017:40(04):48-50

45. Xiong $X$, Tan X, Feng $Y$, Yang Z, Li R, Tian X. Single nucleotide polymorphisms of MTHFR and MTRR67 genes in stroke patients of Tujia nationality and their relationship with serum homocysteine levels. Shandong Pharmaceutical. 2019;59(09):19-22.

46. Xu Q. Study on the correlation between TCM syndrome differentiation of stroke and MTHFR polymorphism [master]: Hubei University of Chinese Medicine; 2012.

47. Zhang L, Bo S, Zhang J, Nan G. Correlation between N_5,N_(10)methylenetetrahydrofolate reductase (MTHFR) A1298C gene mutation and young ischemic stroke. Jilin Medicine 2007(07):877-878.

48. Zhang J, Guo X, Bi Q. Correlation between polymorphism of methylenetetrahydrofolate reductase gene and plasma homocysteine level and acute ischemic stroke in youth. Chin Stroke J. 2012;7(04):271-7.

49. Zhao J, Zhang D, Wang H. Study on the relationship between polymorphism of methylenetetrahydrofolate reductase gene and ischemic stroke. Laboratory Med Clin. 2017;14(13):1847-50.

50. Gelfand AA, Croen LA, Torres AR, Wu YW. Genetic risk factors for perinatal arterial ischemic stroke. Pediatr Neurol. 2013;48(1):36-41.

51. Akar N, Akar E, Ozel D, Deda G, Sipahi T. Common mutations at the homocysteine metabolism pathway and pediatric stroke. Thromb Res. 2001; 102(2):115-20

52. lin X, LI N, Dong Y. Relationship between Homocysteine,MTHFR Gene Polymorphisms and Atherosclerotic cerebral Infarction. Foreign Medicine (Cerebrovascular Disease Volume). 2004(05):367-70.

53. Biswas A, Tiwari AK, Ranjan R, Meena A, Akhter MS, Yadav BK, et al. Prothrombotic polymorphisms, mutations, and their association with pediatric non-cardioembolic stroke in Asian-Indian patients. Ann Hematol. 2009;88(5):473-8. 
54. Toyoda K, Uwatoko T, Shimada T, et al. Recurrent small-artery disease in hyperhomocysteinemia: widowers' stroke syndrome? Intern Med Tokyo Jpn. 2004;43(9):869-72.

55. Ueland PM, Refsum H. Plasma homocysteine, a risk factor for vascular disease: plasma levels in health, disease, and drug therapy. J Lab Clin Med. 1989;114(5):473-501.

\section{Publisher's Note}

Springer Nature remains neutral with regard to jurisdictional claims in published maps and institutional affiliations.

Ready to submit your research? Choose BMC and benefit from:

- fast, convenient online submission

- thorough peer review by experienced researchers in your field

- rapid publication on acceptance

- support for research data, including large and complex data types

- gold Open Access which fosters wider collaboration and increased citations

- maximum visibility for your research: over $100 \mathrm{M}$ website views per year

At BMC, research is always in progress.

Learn more biomedcentral.com/submissions 